\title{
DEVELOPMENT CONCEPT OF A PORTABLE QUALITY-CONFIRMATION INSPECTION DEVICE FOR AUTOMOTIVE BODY PARTS
}

\author{
B.W. Momang ${ }^{1 *}$ and N.M.Z.N. Mohamed ${ }^{1,2}$ \\ ${ }^{1}$ Faculty of Mechanical Engineering, University Malaysia Pahang, \\ 26600 Pekan, Pahang, Malaysia, *Email: wybarmujahid@ gmail.com \\ Phone: +60198828690 \\ ${ }^{2}$ Automotive Engineering Centre, University Malaysia Pahang, \\ 26600 Pekan, Pahang, Malaysia
}

\begin{abstract}
In order to reduce the checking time required and to reduce human error in the stamping process, this paper proposes the development concept of a portable quality-confirmation inspection device for an automotive body part. The portable device will be designed to reduce human error, as well as the checking time, by incorporating computer programming. The characteristics of the portable checking device are among the significant relevant criteria when inventing a suitable checking device. Since this study uses two different types of sensor, it is necessary to find the correct positioning distance. The sensors will capture the image of a production part and transfer the data into the computer. The data is analyzed to determine whether it satisfies the actual CAD data. If the data does not align with the standard result, the distance of the sensor must be adjusted and calibrated by analyzing the range of the sensor. At the end of this research, the established development concept of a portable quality-confirmation inspection device can be used as a reference and guide for future designs.
\end{abstract}

Keywords: Automotive part; checking fixture; fixture design; fixture verification; gantry system; sensor.

\section{INTRODUCTION}

Checking fixture (CF) design is required in the manufacturing of automotive parts specifically to check that the accuracy of the produced part is according to the parts in the drawing design [1]. It can continually improve the quality of the stamping, as well as setting up inspection standards for retail component suppliers and car producers [24]. $\mathrm{CF}$ is also very helpful to control the quality of the final or half-finished product during the processing procedure $[2,5]$. Checking fixture design (CFD) not only varies with the products and the process plan, but is also a complicated and high-precision process. It is crucial to develop an intelligent checking fixture design system to improve the efficiency and quality of the product [4]. It is also important to solve the key technical problems in design verification [5]. Automotive body panel quality is crucial, especially in the automotive industry where there is a radically shortened product development cycle time [4, 6]. It also remains an important differentiating factor between the best performing companies and the rest of the industry [7, 9]. Automotive body panel quality processes importantly try to reduce costs, without sacrificing productivity and reputation in the global market. The quality strategy plays an important role in capturing customer satisfaction, which can potentially lead to increased sales 
growth and market share [8-10]. Quality assurance is the practices aimed at reducing defects and improving performance features of products, whereas reliability assurance is aimed at minimizing suppliers' production and delivery failures $[4,9]$.

Besides that, the production of new automotive related parts is increasingly dependent on rapid product development. Thus, automotive part inspection has become crucial $[6,10]$. This review is important to ensure that the automotive section follows and satisfies the quality requirements [11]. Accuracy checking represents a general procedure of investigation in the automotive field. The presence of a checking device such as a 3D-scanner helps make the process of efficiency control much easier $[12,16]$. The development of this scanner helps industry to make accurate verifications. However, the purchase of a 3D-scanner requires a substantial investment so only large companies can afford to buy them [13-15]. The greatest challenge faced is to provide a checking device that is affordable even for small companies [14]. Lastly, the verification method used nowadays is a device that allows the inspection of automotive parts by comparing parts of the geometry and features of the fixtures [8, 15]. The invention of the checking fixture device is in reponse to the current economic climate that requires companies to invest in low-cost checking devices [16]. Therefore, this research work concentrates purely on the development of a portable qualityconfirmation inspection device. The present paper emphasizes the design of a gantry system that acts as a framework that supports the structure of the checking device and has a stable position for accuracy checking on the production part. Parameters such as the design of a gantry system, the distance of the sensor of the production parts, the type of data analysis used, and suitable material, should be considered within this project. In addition, it is aimed to to reduce the checking time required for automotive panels and to reduce human error.

\section{DEVELOPMENT CONCEPT}

\section{Portable Checking Fixture Design}

The fixtures consist of four essential components: the base plate, support, clamp and locators. In order to ensure the stability and immobility of the workpiece during machining, the way to place the components onto a workpiece needs to be measured $[17,18]$. The fixture design process has four important steps: setup planning, fixture planning, unit design and verification (see Figure 1). The identification of the machining setup of the non-moving parts in each configuration is known as setup planning [4]. Fixture planning can define the fixed physical requirement and layout plan and prevent collision. Unit design is the definition of the locating and clamping units of a fixture secured on the base plate [17]. To ensure that the developed fixture design satisfies the fixturing requirements, a verification process is needed. The step intended to prevent fixture component deformation is known as the unit design stage [18]. As an example, distortion as a result of the clamping forces and machining must be avoided, and the tolerances of the locating units should be such that the accuracy of the location can satisfy the essential requirements of the specification of clamping and locating the unit design [17]. The method for verifying the design of the fixture is involves analyzing the fixture workpiece's stability, deformation, tolerance achieved and geometric constraints: (1) The process of design includes many factors, so proper models for analysis of the process are not easy to implement; (2) the design constraints are individually considered, but as a result of being regarded together, some constraints are 
contradictory; and the fixture design is closely connected to other works in a manufacturing system like CAM $[4,18]$.

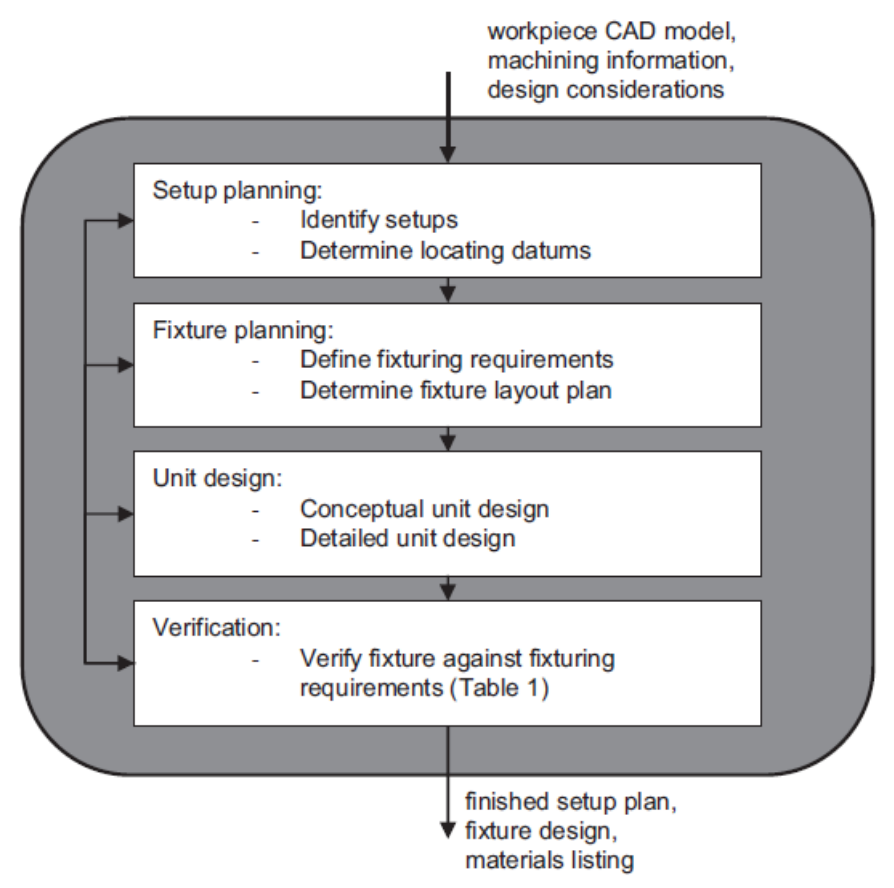

Figure 1. The fixture design process [4].

\section{Gantry System Preparation}

The gantry system is a framework that supports the structure of the checking device and the automotive body part. The design of the gantry system is important because it acts as a workspace for the operation of the checking equipment. It is often also a large workspace, since it can fill an entire site with the required equipment for the monitoring device. It also provides better positioning accuracy of the sensor with respect to the production part. These are the reasons why gantry systems are used in the placing and positioning of the applications. They are also easier to program and set up. The design of the gantry system begins as a sketch on paper. The idea of the gantry system is illustrated based on a current gantry system such as a 3D-scanner. In this project, the CFD needs to be portable so that it is easy to carry or transfer from one location to another. In this project, a first design was proposed, and then improvements were made based on it. The final design must satisfy all the criteria for the checking device. All three models were designed using the SolidWorks2013 software. The drawing was made in parts in SolidWorks2013 and then assembled. Some minor adjustments were made to the dimensions so that the parts would fit better. Figure 2 shows the design of the gantry system. After making some modifications to the design of Figure 2(a), 2(b) and 2(c), the design of Figure 2(d) was finally proposed. It uses the same mechanism as Design 1, but the pulley arrangement used is more sophisticated and better organized. The presence of a hole in the bottom surface is the same as in Design 2, as its function is to put the mold on the production part. This improved gantry system design seems more portable and substantial than the previous designs. 


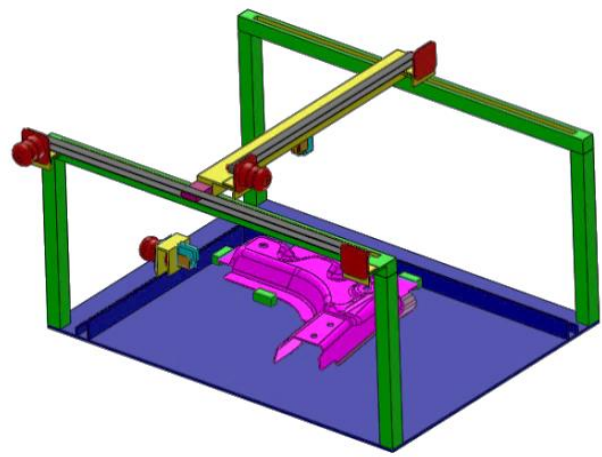

(a)

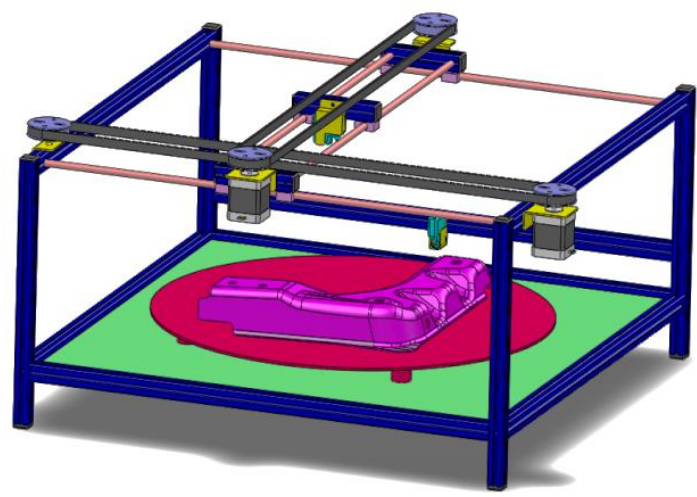

(c)

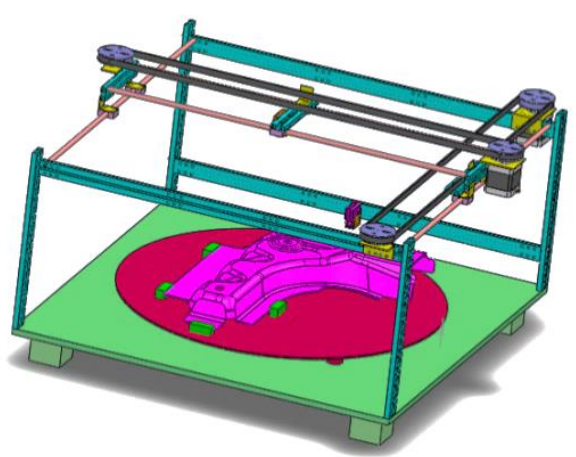

(b)

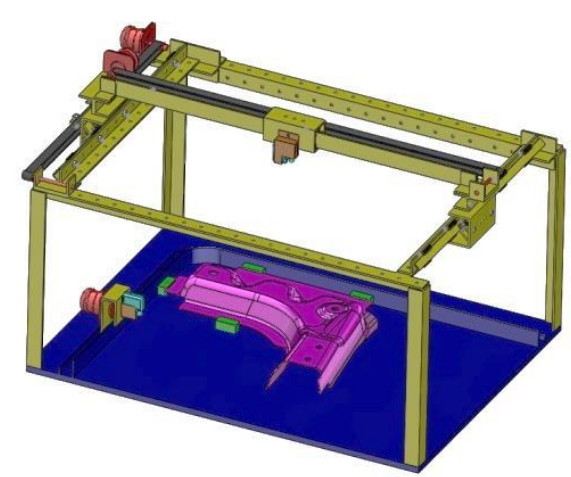

(d)

Figure 2. Gantry system design: (a) Design 1; (b) Design 2; (c) Design 3; (d) Design 4.

A roller connects the pulley to the motor and when the engine starts, the attached roller and pulley will move the top plate along the y-direction. The top plate illustrates the presence of the motor. The motor is intended to move along the top plate ( $\mathrm{x}$ direction) of the checking device. Since the sensor is small in size, it is attached to the body of the carrier. Thus, the sensor will follow the direction of the carrier as it moves. The railway at the bottom surface of the plate needs to be curved to allow the motion of the motor with the sensor. In this design, a gear was used to move the sensor following the bending plate. The gantry system design used an angle iron as the framework supporting the structure of the checking device. Using this angle iron as a structure or frame for the gantry testing method is not only convenient in construction, but also saves much time and labor. It is also light, good quality and comes at a reasonable price. Besides that, the angle iron has high mechanical strength and an attractive appearance. The rational design with the presence of holes helps to adjust the height of the gantry device, using only a bolt and nut as a fastener. The fabrication process is done according to this Design 4.

\section{Automotive Body Part}

Figure 3 displays the reinforced front panel used during the testing process. The accuracy of the automotive part needs to be checked to ensure that it satisfies the required standard. The trim lines and the gap in the reinforced front panel were measured by the sensor provided and compared with the standard result. The reinforced front panel above is the maximum size of part that can fit on the bottom surface of this 
portable checking device. The size is about $280 \mathrm{~mm}$, and most automotive body parts below that size can fit into the. A mold of the part needs to be cast to hold the part in place so that it is motionless. Planning of the setup of the automotive body part involves determining setup features, where an individual setup defines the features used in subsequent phases without having to alter their position manually [21]. Moreover, the remaining stages of the design process focus on developing specific fixtures for each setup that secure the automotive body part being checked. The key outputs from the setup planning phase are the identification of each required configuration, such as the surfaces to be checked and definition of the surface locations $[4,21]$.

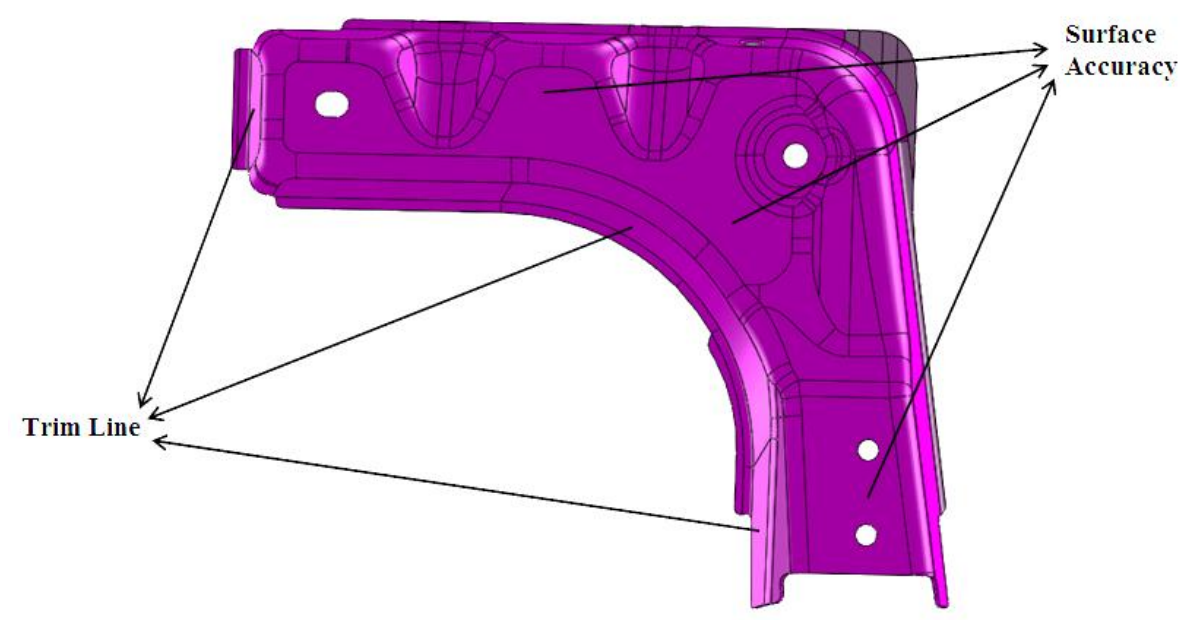

Figure 3. The reinforced front panel.

\section{Sensor}

In this project, two sensors were used to target and scan the automotive body part, namely a photoelectric sensor and a laser distance sensor. The photoelectric sensor uses infrared as its visual light while the laser distance sensor uses a laser to scan the automotive parts. The photoelectric sensor, shown in Figure 3(a), is sensitive to distance and must not be more than $50 \mathrm{~mm}$ distant when examining the automotive section [20]. The distance sensors are used in conjunction with a reflector, directly on the target surface, or depending on both the sensor and the application requirements. The laser scanner uses a beam to measure the distances, which is bounced back to the scanner by the object [20]. The distance measured is given to millimeter accuracy by measuring the phase shift between the sending and receiving beam. The sensors work based on the triangulation principle to measure an object directly, as shown in Figure 3(b).

\section{Arduino and Stepper Motor}

The motor is an essential equipment, needed to run the overall mechanism of this project. The motor must be selected to suit the type of programming used. Since the Arduino is used in this project, a stepper motor is more suitable than a DC motor and for this study a unipolar stepper motor is used. This requires an external control circuit or microcontroller such as the Arduino to energize individually each electromagnet and make the motor shaft turn. Besides, the stepper motor is slow and has precise rotation. It is also easy to control and set up. In this project, the motor needs to be in high torque, but at slow speed, so the stepper motor was chosen as it satisfies all the required 
mechanisms. The Arduino Mega $2569 \mathrm{R} 3$ is used as a driver to run the stepper motor and it acts as the system memory, which enables control of the motion of the stepper motor when input is applied to the system, as shown in Figure 3(c).

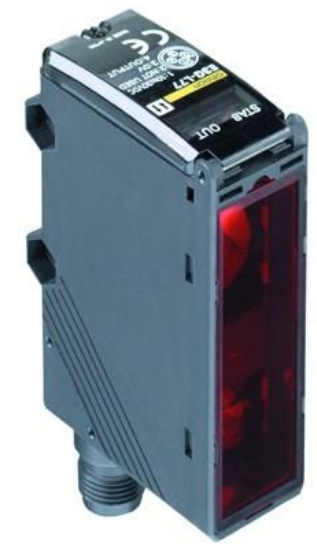

(a)

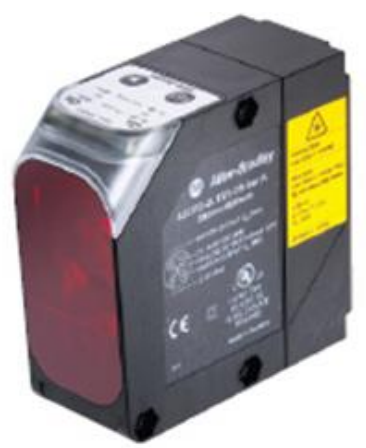

(b)

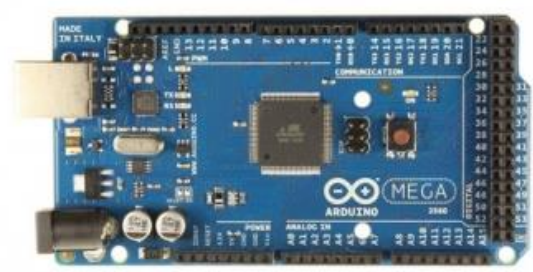

(c)

Figure 3. Electrical components: (a) Photoelectric sensor; (b) Distance sensor; (c) Arduino Mega 2560 R3.

\section{Checking System Configuration}

To ensure that this process performs efficiently, all the components used must be set up properly; the computer system is made ready with Arduino and Visual Studio, software for the checking system and data collection. Besides that, a sufficient power supply is required to run the machine, instrument, stepper motor and distance sensor and enable them to function properly. In addition, the gantry system should be in good condition and placed on a smooth ground surface. All the connections between the computer and gantry system must be correct to ensure that all the applications function properly, as shown in Figure 4. Lastly, after all the components have been set up, testing can be done by running the checking fixture device. The distance sensors will scan as many as points as can be automatically displayed on the computer monitor. The sensors will capture the image of a production part and transfer the data into the computer. The data is analyzed to determine whether it satisfies the actual CAD data. If the data does not align with the standard result, the distance of the sensor must be adjusted until it satisfies the CAD data.

Commonly, two types of data are generated by the CF - trim line and gap analysis. The data is crucial to the assembly process with other parts and components. The data will indicate the critical areas that are out of tolerance and require improvement to the molds and dies. A case study of the checking process based on a Reinforced Front Pillar Panel is shown in Figure 5. The sample results indicate that twelve areas (Points 21, 22, 23, 24, 27, 28, 29, 30, 31, 32, 33 and 34) need to be improved. The remaining areas are in good condition, and no further action is required in these areas. Then, the system provides some kinematic and tolerance analysis tools to calibrate the design of the model. The $\mathrm{CF}$ generates the quality analysis of the automotive body part that guides the operation of inspection. 


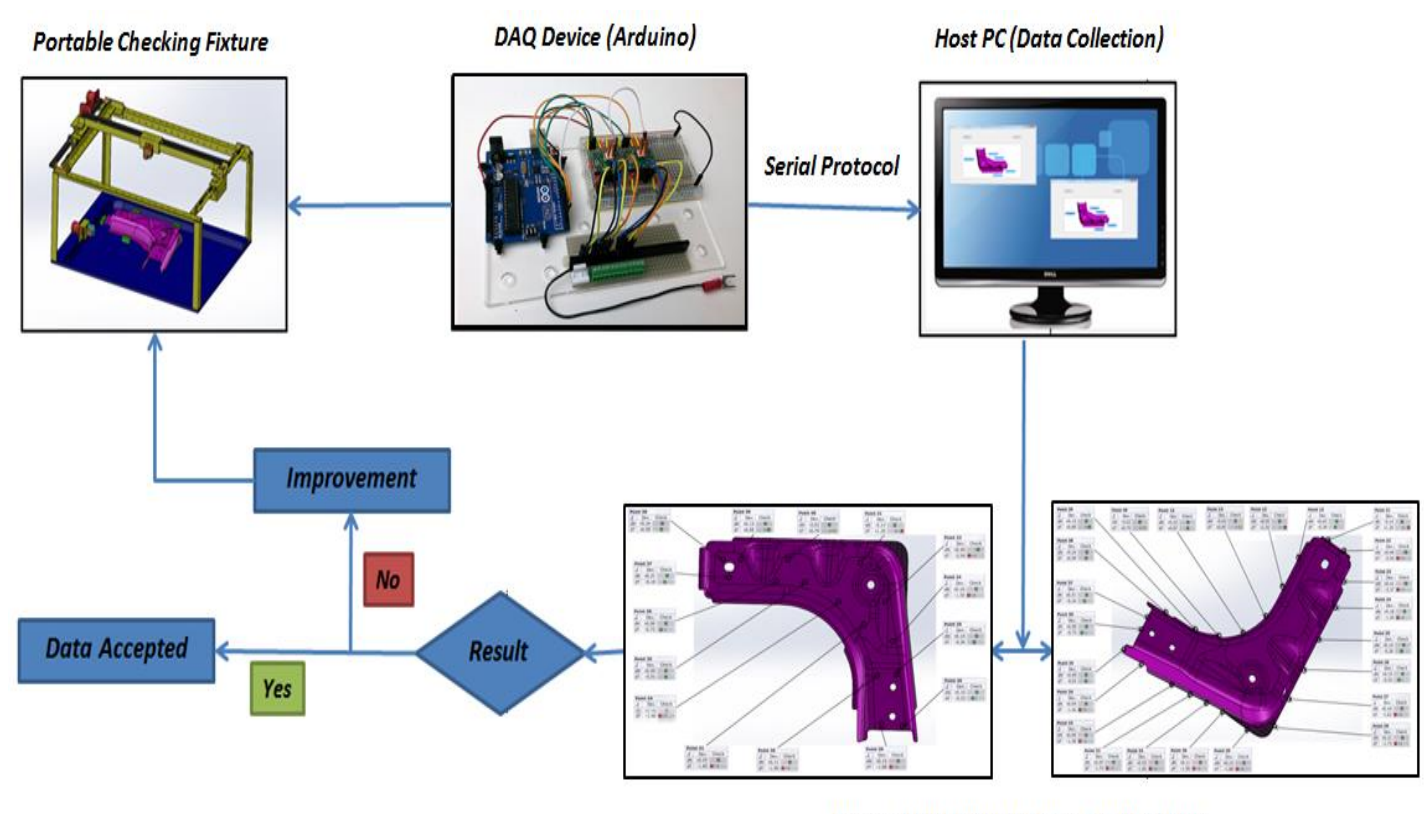

Automotive Body Part Data and Analysis

Figure 4. Checking system flow.

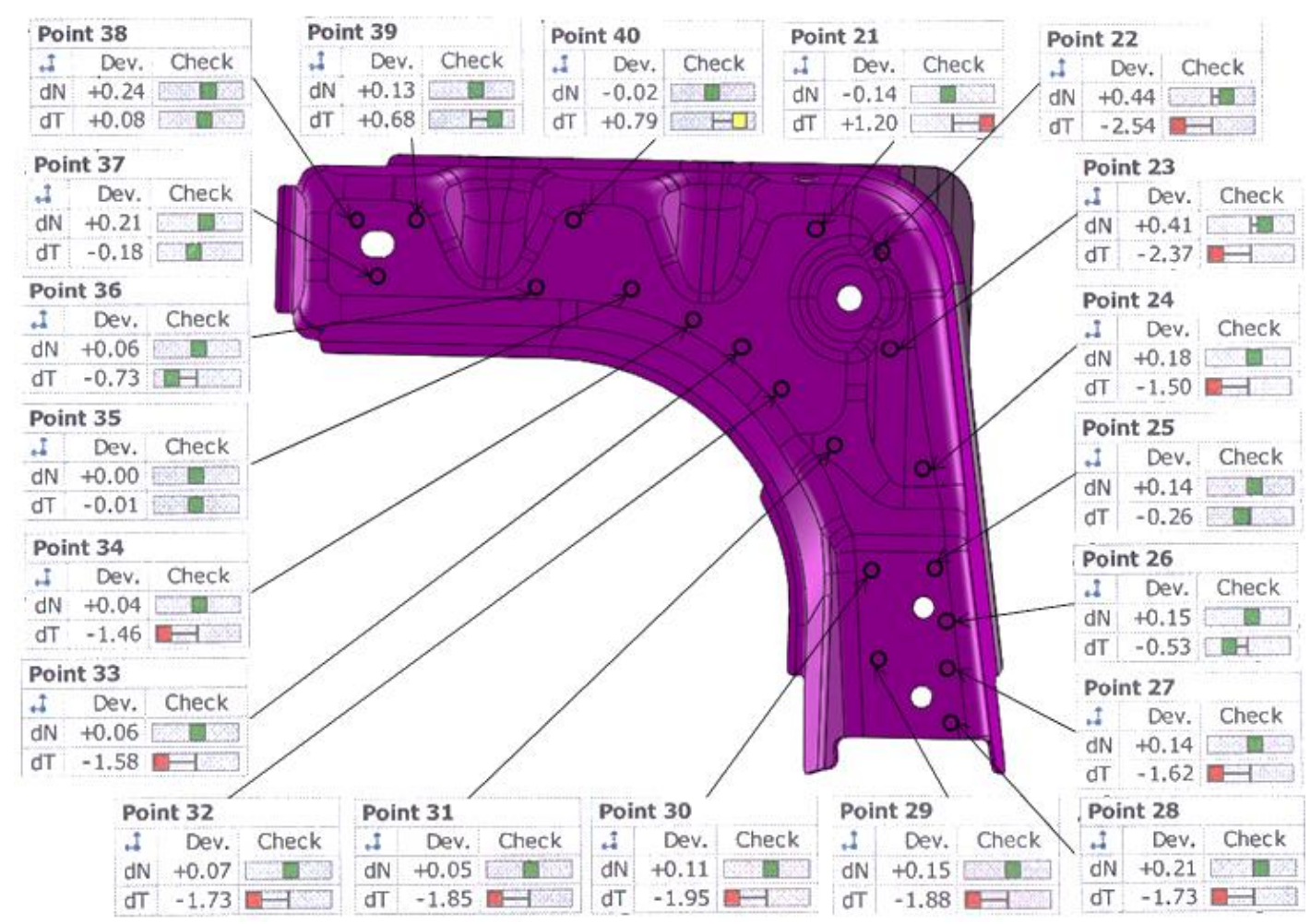

Figure 5. Results of the automotive body part checking.

\section{CONCLUSIONS}

This paper aimed to introduce the development concept of a portable qualityconfirmation inspection device for an automotive body part. To invent an excellent 
portable checking device, its characteristics and the design of a gantry system need to be considered. The design of the gantry system is essential because it acts as the workspace for the operation of the checking devices and as the framework that supports them. The data is analyzed using computer software to determine whether it satisfies the actual CAD data. If the data does not align with the standard result, the distance of the sensor must be adjusted until it satisfies the CAD data. To achieve an efficient method, integration of all the four steps of fixture design (setup planning, fixture planning, unit design, and verification) is needed. The fixture design task must add to the overall process of manufacturing to achieve the best solution for fixture design. Finally, a Reinforced Front Pillar Panel CF design is taken as a case study to demonstrate its feasibility and practicability.

\section{ACKNOWLEDGEMENTS}

The authors would like to be obliged to University Malaysia Pahang for providing laboratory facilities and financial assistance under project no. RDU130316.

\section{REFERENCES}

[1] Mohamed, N.M.Z.N. And Khan, M. K. The development of a hybrid knowledge based system for the design of a Low Volume Automotive Manufacturing (LVAM) system, International Journal Intelligent Systems Technologies and Application. 2012; 11:17-35.

[2] Jahanzaib, M. Coping with medium volume-low variety manufacturing environment in the automobile industry of Pakistan. PhD. University of Engineering and Technology; 2008.

[3] Rong, Y. K., S. Huang, and Z. Hou. Advanced computer-aided fixture design. Boston, Amsterdam: Elsevier Academic Press. Shannon, C. E., and W. Weaver. 1959. The Mathematical Theory of Communication. New York: Citeseer; 2005.

[4] Kang. Y, Rong.Y, Yang.J.C. Computer-aided fixture design verification. Part 1. The framework and modelling. The International Journal of Advanced Manufacturing Technology. 2003; 21: 827-35.

[5] Amoako-Gyampah, K. And Acquaah, M. Manufacturing strategy, competitive strategy and firm performance: An empirical study in a developing economy environment. International Journal of Production Economics. 2008; 111(2): 57592.

[6] González-Benito, J. And Dale, B. Supplier quality and reliability assurance practices in the Spanish auto components industry: a study of implementation issues. European Journal of Purchasing \& Supply Management. 2001; 7(3): 18796.

[7] Sweeney, K. And Grunewald, U. The application of roll forming for automotive structural parts. Journal of Materials Processing Technology. 2003; 132 (1-3): 915.

[8] Shivpuri, R. And Zhang, W. Robust design of spatially distributed friction for reduced wrinkling and thinning failure in sheet drawing. Materials \& Design. 2009; 30 (6): 2043-55.

[9] Kwong, C. K., et al. A genetic algorithm based knowledge discovery system for the design of fluid dispensing processes for electronic packaging. Expert Systems with Applications. 2009; 36: 3829-38. 
[10] Mervyn. F, Kumar A.S, Nee A.Y. An adaptive fixture design system for integrated product and process design. IEEE International Conference on Automation Science and Engineering. 2005; 87-92.

[11] Boyle. I, Rong. Y, Brown. D. C. A review and analysis of current computer aided fixture design approach. Robotics and Computer-Integrated Manufacturing. 2011; 27:1-12.

[12] Selvakumar. S, Arulshri. K, Padmanaban. K, Sasikumar. K. Design and optimization of machining fixture layout using ANN and DOE. The International Journal of Advanced Manufacturing Technology. 2013; 1-14.

[13] Zhang. Y, Hu. W, Rong. Y, Yen. D. W. Graph-based set-up planning and tolerance decomposition for computer-aided fixture design. International Journal of Production Research. 2001, 39: 3109-26.

[14] Xiong. L, Molfino. R, Zoppi. M. Fixture layout optimization for flexible aerospace parts based on self-reconfigurable swarm intelligent fixture system. The International Journal of Advanced Manufacturing Technology. 2013; 1-9.

[15] Boyle. I, Rong. K, Brown. D.C. CAFixD: A case-based reasoning fixture design method. Framework and indexing mechanisms. Transactions of the ASME-SComputing and Information Science in Engineering. 2006; 40-8.

[16] Bi. Z, Zhang. W. Flexible fixture design and automation: review, issues and future directions. International Journal of Production Research. 2001; 39: 286794.

[17] Kang. Y, Rong. Y, Yang. J.C. Computer-aided fixture design verification. Part 2. Tolerance Analysis, International Journal Advanced Manufacturing Technology. 2003; 21:836-41.

[18] Kang. Y, Rong.Y, Yang. J.C. Computer-aided fixture design verification. Part 3. Stability Analysis. The International Journal of Advanced Manufacturing Technology. 2003; 21: 842-49.

[19] Hou, J. L., and A. Trappey. Computer-aided Fixture Design System for Comprehensive Modular Fixtures. International Journal of Production Research. 2001; 39(16): 3703-25.

[20] Wolfgang. B and Andreas. M. Investigating laser scanner accuracy. Institute for Spatial Information and Surveying Technology, FH Mainz, University of Applied Sciences, Mainz, Germany; 2002.

[21] Yao. S, Han. X, Yang Y, Rong.Y.K, Huang.S, et al. Computer aided manufacturing planning for mass customization: part 2, automated setup planning. The International Journal of Advanced Manufacturing Technology. 2007; 32: 205-17. 